Eur. J. Clin. Chem. Clin. Biochem.

Vol. 32, 1994, pp. 749-758

(c) 1994 Walter de Gruyter \& Co.

Berlin - New York

\title{
Glucose Intolerance in Liver Cirrhosis: Role of Hepatic and Non-Hepatic Influences
}

\author{
By M. J. Mïller ${ }^{1}$, M. Pirlich ${ }^{2}, H . J$. Balks $^{3}$ and O. Selberg ${ }^{4}$ \\ 1 Abteilung Gastroenterologie und Hepatologie \\ 2 Abteilung Anaesthesiologie \\ ${ }^{3}$ Abteilung Klinische Endokrinologie \\ ${ }^{4}$ Abteilung Klinische Chemie II \\ Medizinische Hochschule Hannover; Hannover, Germany
}

(Received November 24, 1993/July 18, 1994)

Summary: Oral glucose tolerance was tested in a heterogeneous group of 108 patients with liver cirrhosis. Data were compared with those from 181 subjects without liver disease ( $44 \%$ normal, $35 \%$ impaired glucose tolerance and $21 \%$ type 2 diabetes mellitus). In cirrhosis, $27 \%$ of the patients had normal, $36 \%$ had impaired glucose tolerance, and $37 \%$ were diabetic. There was no association between glucose intolerance or diabetes and the aetiology of cirrhosis, the duration of the disease, the biochemical indicators of hepatocyte damage, cholestasis and/or liver function. Only weak associations were found between the results of quantitative liver functions tests (caffeine, xylocaine ${ }^{\circledR}$, indocyanine green) and basal and post load glucose and insulin concentrations. Cirrhotics with 1st degree relatives with type 2 diabetes mellitus $(n=16)$ did not show an increased prevalence of diabetes. Older and/or malnourished patients were more frequently glucose intolerant. Using the plasma glucose concentration 120 minutes after glucose load as the dependent variable, multivariate regression analysis showed that $54 \%$ of its variance is associated with the following variables: basal plasma glucose $(36 \%)$ and free fatty acid concentration $(5 \%)$, age (3\%), basal glucose oxidation rate (3\%), muscle mass $(3 \%)$ and plasma free glycerol at 120 minutes after glucose load (3\%). By contrast, the clinical state of the patients (i. e. the CHILD-Pugh score) accounted for only $2 \%$ of the variance. We conclude that glucose tolerance is variable in cirrhosis. After manifestation of liver disease, glucose intolerance or diabetes cannot be explained by the clinical, histological or biochemical signs of liver disease.

\section{Introduction}

Liver cirrhosis is frequently associated with secondary diabetes, and about $50-80 \%$ of the patients show glucose intolerance. Overt diabetes is found in 10 to $30 \%$ of the patients and is two to four times more prevalent than in the general population $(1-4)$. Most authors consider an increased systemic appearance of glucose and insulin to be the primary abnormality. Peripheral hyperinsulinaemia and postprandial hyperglycaemia then cause insulin resistance. This scenario partly resembles the chain of events known from type 2 diabetic patients (non-insulin dependent diabetes mellitus). Although numerous studies have been performed in this area, a number of questions remain unresolved. First, a considerable number of cirrhotic patients do not show manifest disturbances in glucose metabolism and it is unclear whether glucose intolerance or even diabetes always develops with advanced liver disease. Second, the possible contribution of different aetiologies of cirrhosis has to be taken into account, since insulin may exert different metabolic effects in different subgroups of patients (5). Furthermore, the impact of sex, age and the duration of the disease, are not known. Third, individual patients at high risk of developing diabetes mellitus (i. e. patients with 1 st degree relatives with diabetes mellitus) have to be considered separately. Fourth, the nutritional state is frequently reduced and about $70 \%$ of patients with cir- 
rhosis show some signs of malnutrition (6-8). Surprisingly, most studies try to ensure that there is no nutritional difference between patients and controls. Malnutrition is known to contribute to insulin resistance in diabetic patients (9) and also to some metabolic alterations observed in cirrhosis $(10,11)$.

The present study was performed on 108 patients with liver cirrhosis. Age, sex, the aetiology of cirrhosis, the duration of disease, hepatocyte damage, cholestasis, liver function and splanchnic circulation, a possible family history of diabetes mellitus and the nutritional state as assessed by body composition analysis were all investigated and taken into account. Data were compared with those of 80 normal controls, 63 subjects with impaired glucose tolerance and 38 patients with non-insulin dependent diabetes mellitus.

\section{Methods}

Patients and study design

Patients with liver cirrhosis $(n=108)$ were investigated and compared retrospectively with a control group of 181 subjects with normal liver function and no history of liver and endocrine diseases. None of the cirrhotic patients had overt diabetes mellitus before manifestation of the liver disease. The control group consisted of 80 subjects with normal and 63 with impaired glucose tolerance. 38 subjects had non-insulin dependent diabetes mellitus.

The biological and physical characteristics of the different groups are given in table 1. All patients were in a stable clinical condition. They were admitted to the Medizinische Hochschule Hannover between October 1989 and December 1990, because they were considered as potential candidates for elective liver transplantation. An intensive clinical and laboratory assessment was performed within a 2 to 3 week period (12). On examination all patients had a weight-maintaining diet including $200 \mathrm{~g}$ carbohydrates and a protein content of at least $0.8 \mathrm{~g} / \mathrm{kg}$ body weight per day for 1 week before the glucose tolerance test. All drugs known to affect glucose metabolism were withdrawn at least 24 hours before the glucose tolerance test. The clinical classification was based on the plasma concentrations of bilirubin and albumin, the prothrombin time and the occurrence of ascites, and clinical signs of encephalopathy (i.e. the CHILD-Pugh score (13)). Moderate $(<2.51)$ or severe $(>2.5 \mathrm{l})$ volumes of ascites were found by ultrasound investigation in 44 and $19 \%$ of the patients, respectively. An oral glucose tolerance test (glucose load $1 \mathrm{~g} / \mathrm{kg}$ body weight; $1 \mathrm{~g}$ glucose $+4 \mathrm{ml}$ $\mathrm{H}_{2} \mathrm{O}$ ) was performed at 8.00 a.m. after an overnight fast. Blood was collected through a butterfly needle introduced into an antecubital vein. Samples were drawn before and 60 and 120 minutes after the oral glucose load. Aliquots were transferred into different tubes placed on ice for the determination of plasma glucose, insulin, C-peptide, lactate, free fatty acids, free glycerol and $\beta$-hydroxybutyrate.

\section{Assessment of liver function}

Liver function was assessed by standard biochemical tests, as well as by the use of quantitative tests of liver function $(8,12,14)$. Indocyanine green $(0.5 \mathrm{mg} / \mathrm{kg}$ body weight), caffeine $(3 \mathrm{mg} / \mathrm{kg}$ body weight) and xylocaine (1 mg/kg body weight) were injected intravenously on different occasions. The formation of the lidocaine metabolite, monoethylglycinexylidide was measured 15 minutes after xylocaine ${ }^{\circledR}$ injection (15).

\section{Assessment of the nutritional and metabolic state}

Nutritional state was assessed by standard anthropometric procedures (triceps skinfolds and mid-arm circumference), the measurement of 24-hour urinary creatinine excretion as an estimate of skeletal muscle mass and bioelectrical impedance analysis, using a radiofrequency current of $800 \mu \mathrm{A}$ at a $50-\mathrm{kHz}$ frequency between a set of electrodes attached to the dorsum of the hand and foot (Akern, RJL body composition analyser, Data Input, Frankfurt, Germany $(8,12)$ ). In addition, total body potassium was determined in a subgroup of 26 patients in a whole body counter with a precision of $2 \%(8)$. Figure 1 shows a close association between body cell mass derived from total body potassium and bioelectrical impedance analysis. This is unaffected by the presence of ascites. However the accuracy of bioelectrical impedance analysis has been questioned in cirrhotic patients with ascites (16). In contrast, paracentesis has only minor effects on bioelectrical impedance analysis data (8). This is because different segments of the body differently contribute to whole body resistance, e.g. the arm contributes as much as $45 \%$ but the trunk is responsible for only $11 \%$ of whole body resistance (17). Therefore several litres of ascites have only minor effects on whole body bioelectrical impedance analysis. Resting energy expenditure was assessed after an overnight fast following the procedural issues described elsewhere (18), using an indirect calorimeter (Deltatrac Metabolic Monitor, Datex Instruments, Helsinki Finland).

\section{Laboratory methods}

Enzymes, substrates and hormones were assessed using standard biochemical or radioimmunological procedures as previously described $(8,12,19)$.

\section{Mathematical and statistical analysis}

All data were recorded in a database system using a personal computer, and statistical analyses were performed using the SPSS/PC 4.0. Data are given as means \pm SD if not indicated otherwise. The Mann-Whitney $\mathrm{U}$ test was used for comparison between groups, and $p<0.05$ was considered to be significant. Multiple comparison between groups of controls and patients were performed by ANOVA and a subsequent LSD test. Spearman's correlation coefficient was calculated for testing the relationship between different quantities in a bivariate regression model. In order to describe the covariations of the quantities investigated, correlation coefficients

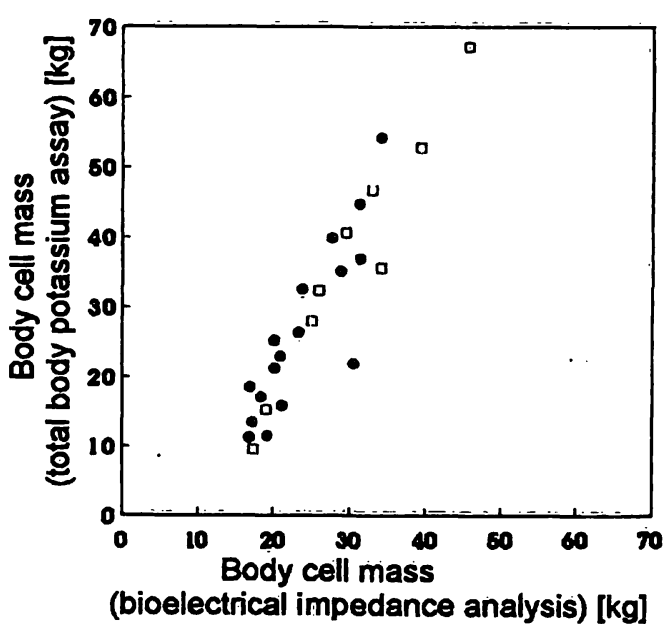

Fig. 1 Correlation of body cell mass, calculated from bioelectrical impedance analysis, and total body potassium.

Correlation between body cell mass calculated from bioelectrical impedance analysis and total body potassium in a subgroup of 26 patients with [0] and without [ $[0]$ significant amounts of ascites ( $>2.5$ litre as determined by ultraşound). $r=0.93(p<0.001)$. 
between respective quantities were calculated and processed by factor analysis and subsequent varimax rotation. In addition, the plasma glucose and insulin concentrations at 120 minutes after glucose load (dependent variables) and their possible determinants (plasma concentrations of measured hormones and metabolites, age, sex, body composition indicators, liver function, CHILD-Pugh score, plasma substrate and hormone concentrations and basal substrate oxidation rates) were subjects in a stepwise regression analysis.

\section{Results}

The biological and physical characterisation of the study population is given in table 1 . Subjects and patients with normal glucose tolerance were younger than those with impaired glucose metabolism. In addition, the mean age of a small subgroup of patients with Budd-Chiari syndrome was lower than the age of the other subgroups. Twenty-seven percent of patients with liver cirrhosis and $44 \%$ of the control group showed normal glucose tolerance; 36 and $35 \%$ had impaired glucose tolerance, whereas 37 and $21 \%$ were diabetic, respectively (fig. 2). The frequency of impaired glucose tolerance was of the same order of magnitude in all groups of cirrhotic patients $(21-57 \%$, tab. 2). Glucose intolerance and also diabetes mellitus were associated with basal and post-

Tab. 1 Biological and physical characterization of the study population.

\begin{tabular}{llll}
\hline $\mathrm{n}$ & $\begin{array}{l}\text { Age } \\
\text { (years) }\end{array}$ & $\frac{\mathrm{Sex}}{\delta{ }^{2}}$ & $\begin{array}{l}\text { Body mass } \\
\text { index } \\
\left(\mathrm{kg} / \mathrm{m}^{2}\right)\end{array}$ \\
\hline
\end{tabular}

Control group

Glucose tolerance normal

impaired

\section{0}

63

$39.7 \pm 12.9 \# \quad 3446$

diabetic
$49.2 \pm 12.8$

3528

$25.8 \pm 4.2$

$26.5 \pm 3.7$

Liver cirrhosis

All

108

$44.0 \pm 12.8$

5355

$23.4 \pm 3.8$

Aetiology of disease

posthepatitic

biliary

ethanol induced

Budd-Chiari

cryptogenic

Clinical state

CHILD A

CHILD B

CHILD C

54

$54 \quad 44.0 \pm 14.5$

$\begin{array}{lll}30 & 24 & 23.7 \pm 3.9\end{array}$

$19 \quad 46.6 \pm 11.4 \quad 3 \quad 16 \quad 21.1 \pm 2.7$

$\begin{array}{lllll}22 & 46.5 \pm 6.9 & 15 & 7 & 24.6 \pm 3.9\end{array}$

$6 \quad 32.2 \pm 11.2 \# \quad 1 \quad 5 \quad 24.6 \pm 6.8$

$\begin{array}{lllll}7 & 39.7 \pm 15.3 & 4 & 3 & 23.0 \pm 2.8\end{array}$

Duration of disease

$$
\begin{aligned}
& <2 \text { years } \\
& 2-5 \text { years } \\
& >5 \text { years }
\end{aligned}
$$

$21 \quad 46.8 \pm 15.2$

$$
49 \quad 45.1 \pm 12.8
$$

$38 \quad 41.4 \pm 11.2$

$7 \cdot 14 \quad 22: 6 \pm 4.1$

$\begin{array}{lll}22 & 27 & 24.1 \pm 4.2\end{array}$

$\begin{array}{lll}24 & 14 & 23.1 \pm 3.4\end{array}$

Glucose tolerance

normal

impaired

diabetic

$23 \quad 39,9 \pm 14.4$

$\begin{array}{lll}10 & 13 & 21.6 \pm 3.9\end{array}$

$\begin{array}{lll}18 & 13 & 24.8 \pm 4.3\end{array}$

$\begin{array}{lll}25 & 29 & 23.3 \pm 3.5\end{array}$

$54 \quad 45.4 \pm 12.8$

$45.4 \pm 12.8$

$29 \quad 35.3 \pm 13.4 \#$

$\begin{array}{lll}14 & 15 & 22.7 \pm 4.6\end{array}$

$\begin{array}{lllll}39 & 45.6 \pm 12.4 & 18 & 21 & 23.7 \pm 3.7\end{array}$

$\begin{array}{lllll}40 & 48.1 \pm 12.4 & 21 & 19 & 23.8 \pm 3.7\end{array}$

\# significant difference between subgroups of patients. prandial (120 minutes after glucose load) hyperinsulinaemia (fig. 3). Postprandial plasma C-peptide concentrations were increased (fig. 3 ).

\section{Liver cirrhosis $(n-108)$}

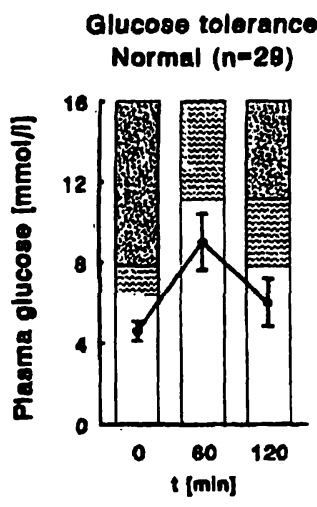

Glucose tolerance

Diabetic $(n=40)$
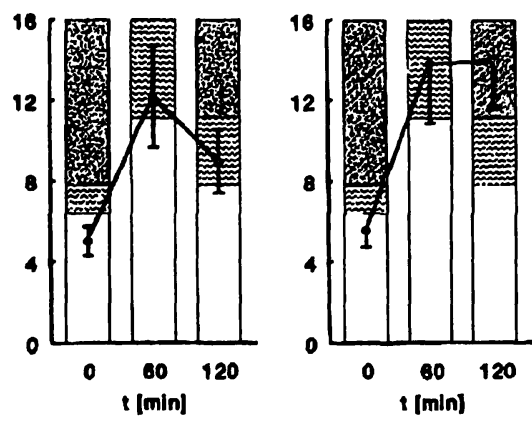

\section{Controls $(n-181)$}
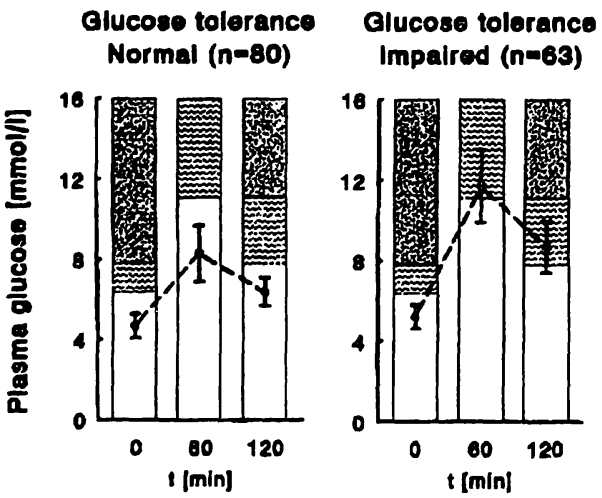

Diabotic $(n-38)$
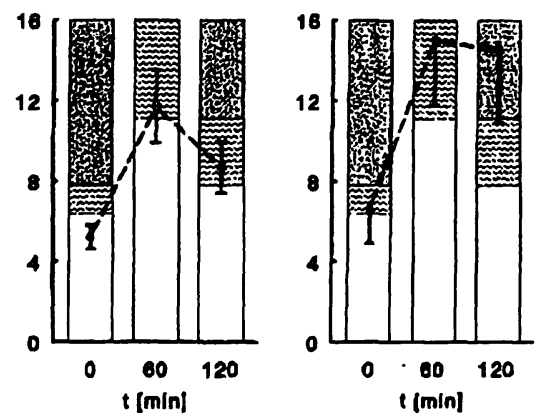

Fig. 2 Glucose tolerance curves in cirrhotic patients and controls. Bar pattern indicates classification of glucose tolerance [ $\square$ normal, .

Tab. 2 Percentage distribution of impaired glucose tolerance in patients with liver cirrhosis.

\begin{tabular}{lll}
\multicolumn{2}{l}{ Glucose tolerance } & \\
\hline normal & impaired & diabetic \\
$\mathrm{n}=29$ & $\mathrm{n}=39$ & $\mathrm{n}=40$ \\
\hline
\end{tabular}

\section{Aetiology of disease}

posthepatitic (\%)

biliary (\%)

ethanol-induced (\%)

Budd-Chiari (\%)

cryptogenic (\%)

$\begin{array}{llr}24 & 39 & 37 \\ 42 & 26 & 32 \\ 18 & 27 & 55 \\ 50 & 50 & 0 \\ 14 & 57 & 29\end{array}$

Clinical state

CHILD A (\%)

CHILD B (\%)

CHILD C (\%)

Duration of disease

$>5$ years $(\%)$ 


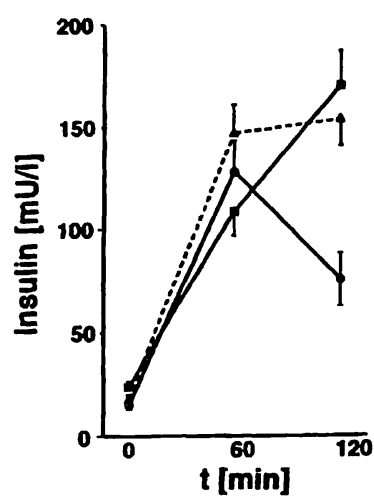

Fig. 3 Insulin and C-peptide response to an oral glucose load. Alterations in serum insulin and C-peptide concentrations and the insulin/C-peptide ratio in response to an oral glucose load in sub-
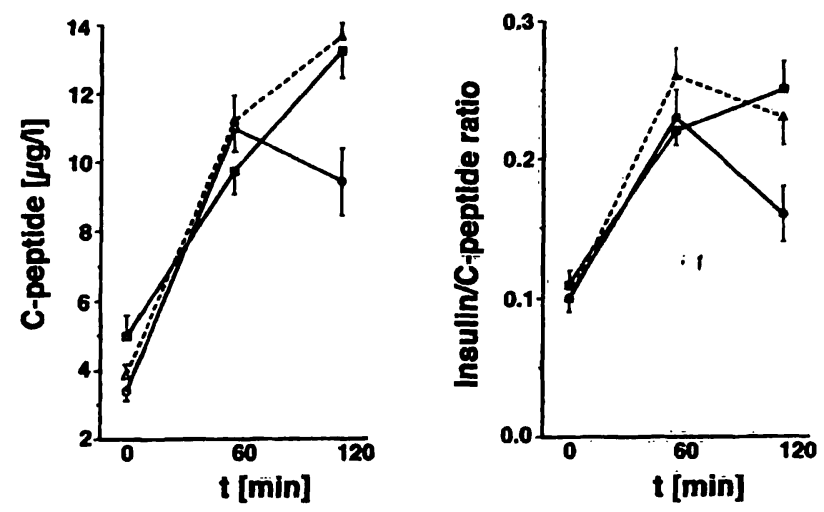

groups of cirrhotic patients [ $-\boldsymbol{O}-$ normal glucose tolerance, --- $\mathbf{- - -}$ impaired glucose tolerance, $-\mathbf{E}-$ diabetic]. Data are means \pm SEM.
Basal and postprandial hyperinsulinaemia were also observed in the diabetic control group and in subjects with impaired glucose tolerance (basal plasma insulin: 8.6 $\pm 4.3,11.1 \pm 5.2^{*}$ and $15.7 \pm 8.7 \mathrm{mU} / 1^{*}$ in healthy controls, "subjects with impaired glucose tolerance and patients with type 2 diabetes mellitus, respectively; *denotes significant differences versus controls, $\mathrm{p}<0.05$ ). The corresponding values 120 minutes after glucose load were $58.2 \pm 39.7,150 \pm 124^{*}$ and $148 \pm 124$ $\mathrm{mU} / \mathrm{l}^{*}$, respectively.

Basal free fatty acids $(0.83 \pm 0.40,0.91 \pm 0.42$ and $\left.1.07 \pm 0.34 \mathrm{mmol} / \mathrm{l}^{*}\right)$ and basal free glycerol plasma concentrations $(0.13 \pm 0.04,0.14 \pm 0.05$ and 0.16 $\left.\pm 0.04 \mathrm{mmol} / 1^{*}\right)$ were increased in diabetic patients with liver cirrhosis when compared with those with normal or impaired glucose tolerance $(* p<0.05)$. However, postprandial (120 minutes after glucose load) plasma concentrations of free fatty acids $(0.14 \pm 0.05$, $0.12 \pm 0.12$ and $0.15 \pm 0.11 \mathrm{mmol} / \mathrm{l})$ and of free glycerol $(0.10 \pm 0.05,0.09 \pm 0.04$ and $0.09 \pm 0.04 \mathrm{mmol} / \mathrm{l})$ showed no significant differences between these subgroups of patients. Plasma $\beta$-hydroxybutyrate concentrations decreased but lactate levels increased after the glucose load in patients with liver cirrhosis (data not shown). However, no significant differences were observed between the different subgroups of patients.

Biochemical tests of liver function, as well as quantitative liver function tests, all deteriorate with deterioration of the clinical state (tab. 3). In contrast, there was no clear picture in subgroups of patients with different degrees of glucose intolerance. However, alanine aminotransferase ${ }^{1}$ ) and albumin were both decreased in the diabetic group (tab. 3). The clearance rates of indocyanine green and caffeine were impaired in diabetic cir-

\footnotetext{
1) Enzyme:

Alanine aminotransferase: $L$-Alanine : 2-oxoglutarate aminotransferase (EC 2.6.1.2)
}

rhotics with no difference in xylocaine ${ }^{\circledR}$ metabolism (tab. 3). Regression analysis showed significant correlations between the plasma glucose concentrations at 120 minutes, the half lives of caffeine $(r=0.28$, $p<0.01)$ and indocyanine green $(r=0.22, p<0.05)$, and the appearance of monoethylglycinexylidide at 30 minutes after injection of xylocaine ${ }^{\circledR}(r=0.21$, $\mathrm{p}<0.05)$. Basal and postprandial $(120$ minutes after glucose load) plasma insulin concentrations were correlated with the half life of indocyanine green $(r=0.38$, $p<0.001$ and $r=0.22, p<0.05$, respectively). No significant differences in the 120 minute plasma glucose and insulin concentrations were found (i) between CHILD A, B and C patients, (ii) patients with different durations of the disease, and (iii) patients with increased vs. normal ammonia and/or methionine levels (data not shown).

Seventy-two percent of the patients had basal insulin concentrations of less than $20 \mathrm{mU} / 1$ serum (mean values: $9.3 \pm 3.5 \mathrm{mU} / \mathrm{l}$ ) and $28 \%$ were considered as hyperinsulinaemic (i. e. basal plasma insulin levels $>20 \mathrm{mU} / \mathrm{l}$; mean: $31.9 \pm 3.7 \mathrm{mU} / \mathrm{l} ; \mathrm{p}<0.001$ ). Differences in basal insulin concentrations were associated with differences in postprandial (120 minutes after glucose load) insulin concentrations (114 \pm 87 and $202 \pm 90 \mathrm{mU} / 1$ for basal insulin levels $<20$ and $>20 \mathrm{mU} / \mathrm{l}$, respectively; $\mathrm{p}<0.01$ ). Significant correlations were observed between basal insulin concentrations and basal glucose $(r=0.43, p<0.001)$, glucose at 120 minutes after glucose load $(r=0.23, p<0.05)$ and insulin at 120 minutes after glucose load $(r=0.47, p<0.001)$. In both the control and the cirrhotic group, plasma insulin levels progressively increased with fasting and postprandial (120 minutes after glucose load) glucose concentrations (fig. 4). Maximal plasma insulin concentrations were attained at a plasma glucose level of about $8 \mathrm{mmol} / \mathrm{l}$ (fig. 4). Thereafter, further increases in glucose were associated with decreases in insulin secretion. The insulin re- 
Tab. 3 Liver function in patients with ljver cirrhosis classified according to the clinical state and glucose tolerance.

\begin{tabular}{lllllll} 
Clinical state & & & & Glucose tolerance & \\
\cline { 1 - 1 } \cline { 6 - 7 } CHILD A & CHILD B & CHILD C & & normal & impaired & diabetic \\
$n=21$ & $n=49$ & $n=38$ & & $n=29$ & $n=39$ & $n=40$
\end{tabular}

Biochemical quantities of liver function

Alanine aminotrans-

ferase (U/l)

Bilirubin $(\mu \mathrm{mol} / \mathrm{l})$

Albumin $(g / 1)$

Prothrombin time (\%)

Methionine $(\mu \mathrm{mol} / \mathrm{l})$

Ammonia (mmol/l)

Quantitative liver function tests

Indocyanine green $t_{1 / 2}(\mathrm{~min})$

Caffeine $t_{1 / 2}(h)$

Monoethylglycinexylidide $(\mu \mathrm{g} / \mathrm{l})^{*}$

\footnotetext{
* measured at 15 minutes after injection of xylocaine ${ }^{\circledR}$.

a $\mathrm{p}<0.05$ vs. CHILD A

b $\mathrm{p}<0.05$ vs. CHILD B
}

$\begin{aligned} 43.9 & \pm 43.9 \\ 136.4 & \pm 135.4^{\mathrm{a}, \mathrm{b}} \\ 33.2 & \pm 5.9^{\mathrm{a}} \\ 47.8 & \pm 12.4^{\mathrm{a} b \mathrm{~b}} \\ 168.0 & \pm 225.8^{\mathrm{a}, \mathrm{b}} \\ 64.2 & \pm 31.2\end{aligned}$

$16.8 \pm 9.4^{a}$

$31.2 \pm 36.1^{\mathrm{a}}$

$15.8 \pm 11.1^{\mathrm{a}}$
$27.2 \pm 11.6^{\mathrm{a}, \mathrm{b}}$
$65.8 \pm 44.6^{\mathrm{a}, \mathrm{b}}$
$7.5 \pm 5.5^{\mathrm{a}, \mathrm{b}}$

$\begin{aligned} 52.4 & \pm 55.0 \\ 105.0 & \pm 143.0 \\ 37.8 & \pm 5.7 \\ 60.9 & \pm 19.9 \\ 161.0 & \pm 248.0 \\ 70.1 & \pm 34.7\end{aligned}$

$33.5 \pm 25.2^{\mathrm{c}}$

$58.2 \pm 73.4$

$38.2 \pm 6.1$

$63.3 \pm 17.7$

$84.9 \pm 58.5$

$64.4 \pm 40.0$
$17.6 \pm 12.5$

$31.6 \pm 33.9$

$14.1 \pm 10.4$
$16.7 \pm 9.4$

$29.2 \pm 19.4$

$15.9 \pm 10.5^{c}$
$31.0 \pm 19.2^{\mathrm{c}}$

$62.7 \pm 62.2$

$34.3 \pm 6.2^{\mathrm{c} . \mathrm{d}}$

$57.0 \pm 16.5$

$89.9 \pm 108.0$

$69.6 \pm 35.6$

\footnotetext{
c $p<0.05$ vs. normal glucose tolerance

d $\mathrm{p}<0.05$ vs. impaired glucose tolerance
}

sponse curve to an oral glucose load (i. e. plasma glucose vs. plasma insulin at 120 minutes after glucose load) was similar in patients with liver cirrhosis when compared with the data obtained in our control group (fig. 4).

No differences in the mean values of the different indicators of the nutritional and metabolic state were found between cirrhotics with different glucose tolerance curves (tab. 4). The plasma glucose concentration at 120 minutes after glucose load was significantly lower in male patients with normal body cell or muscle mass $\left(10.5 \pm 4.1\right.$ and $9.2 \pm 3.1 \mathrm{mmol} / 1^{*}$; plasma insulin concentrations: $113 \pm 70$ and $170 \pm 111 \mathrm{mU} / 1^{*}$ for a muscle mass $<25$ versus $>25 \mathrm{~kg}$, respectively; ${ }^{*} \mathrm{p}<0.05$ ). No significant differences in glucose tolerance curves were obtained for females differing with respect to muscle mass (plasma glucose at 120 minutes after glucose load $9.1 \pm 3.4$ and $10.9 \pm 3.9 \mathrm{mmol} / \mathrm{l}$; plasma insulin concentration $111 \pm 83$ and $161 \pm 109 \mathrm{mU} / \mathrm{l}^{*}$ for a muscle mass $<16$ vs. $>16 \mathrm{~kg}$, respectively; ${ }^{*} \mathrm{p}<0.05$ ). There was no association between the plasma glucose concentration at 120 minutes after glucose load and whole body potassium concentration, either expressed in absolute numbers or as $\mathrm{K}^{+}$concentration in $\mathrm{mmol} / \mathrm{l}$ body water (as determined by bioelectrical impedance analysis) $(r=0.28$ or 0.29 , n.s., $\mathrm{n}=26$; data not shown). Patients with increased fat mass or obesity did not show an increased frequency of glucose intolerance (data not shown). A significant correlation was found between the plasma insulin concentration at 120 minutes after glucose load and fat mass $(r=0.43, p<0.001)$. Comparison of subgroups with increased fat mass (fig. 5) revealed no significant differences in the mean postprandial (120 minutes after glucose load) insulin and glucose responses between controls with impaired glucose tolerance or diabetes with and without obesity. At the same time there was a disproportional and significantly increased postprandial (120 minutes after glucose load) insulin response in obese patients with liver cirrhosis, when compared with patients with impaired glucose tolerance or diabetes alone (fig. 5). Concomitantly, obese and non-obese patients showed similar postprandial (120 minutes after glucose load) plasma glucose concentrations.

There were no significant differences between male and female patients. Regarding the possible contributory factor of age, glucose intolerance and also diabetes mellitus were more frequently seen at advanced age in patients with liver cirrhosis as well as in our control group (fig. 6). This was independent of the duration of the disease. A family history of diabetes mellitus was obtained in 58 patients with liver cirrhosis. Twenty-eight percent of these patients had a positive family history (i. e. at least one 1st degree relative with diabetes mellitus type 2). Although patients with cirrhosis and an increased risk of becoming diabetic showed increased postprandial (120 minutes after glucose load) hyperinsulinaemia (n. s.), the relative frequency of diabetes mellitus was not increased in this subgroup.

Factor analysis with subsequent varimax rotation resulted in 9 factors (factor loading is given in brackets). Factor 1 included the CHILD score $(0.78)$ and the results of quantitative liver function tests $\left(t_{1 / 2}\right.$ indocyanine 

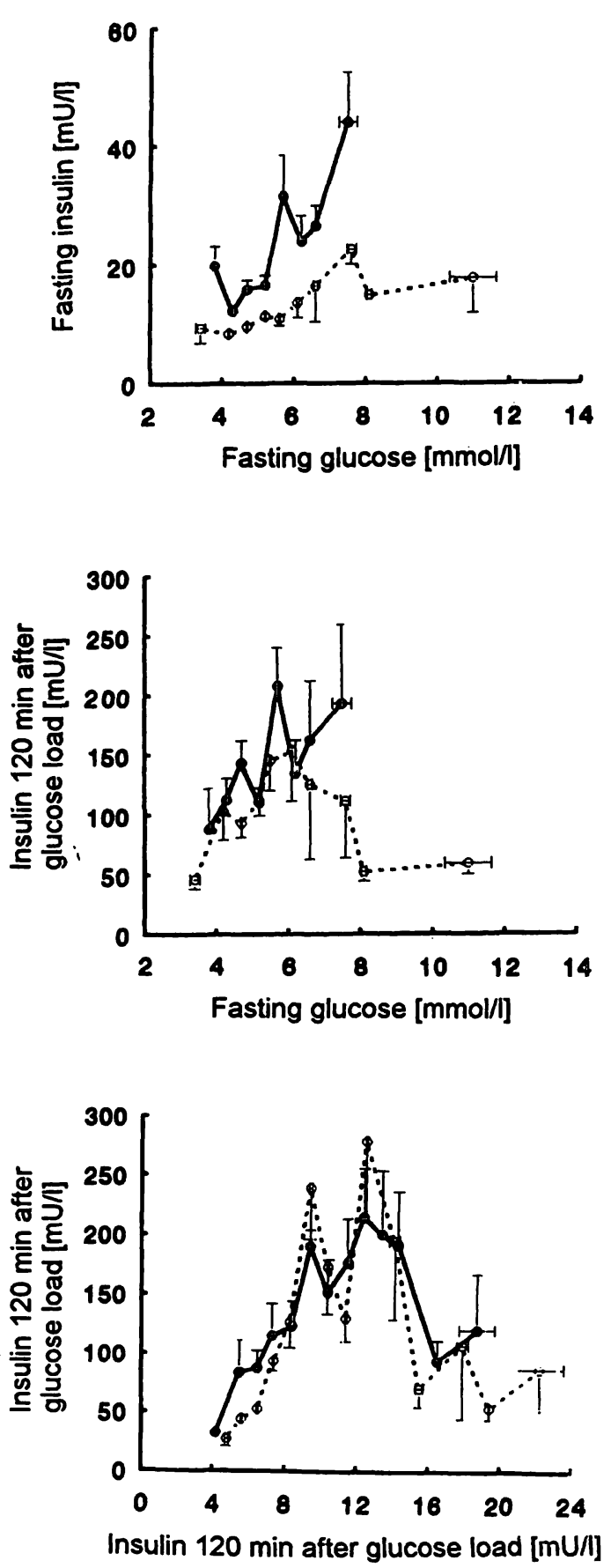

Fig. 4 Relationship between insulin and glucose concentrations in cirrhosis and controls.

Association between fasting glucose and fasting insulin plasma concentrations, between fasting glucose and insulin level at 120 minutes after glucose load, and between glucose and insulin level 120 minutes after glucose load in patients with liver cirrhosis [-0-] and the control group [---O---]. Data have been grouped for glucose concentrations at intervals of $0.5 \mathrm{mmol} / \mathrm{l}$. Data are means $\pm \mathrm{SEM}$.

green: 0.75 ; monoethylglycinexylidide $15 \mathrm{~min}$ after $\mathrm{xy}-$ locaine ${ }^{\circledR}$ injection: $-0.75 ; t_{1} / 2$ caffeine: 0.57$)$. Factor 2 included body cell mass (0.92), fat free mass (0.91), resting energy expenditure $(0.80)$, corrected arm muscle area (0.78), muscle mass $(0.73)$ and sex $(0.70)$. Factor 3 included total body water $(-0.92)$ and fat mass $(0.92)$. Factor 4 included basal (0.71) and postprandial (120 minutes after glucose load) glucose concentration (0.86) and age (0.68). Factor 5 included basal and postprandial (120 minutes after glucose load) concentrations of free fatty acids $(0.53,0.82), \beta$-hydoxybutyrate $(0.63,0.57)$, and free glycerol $(0.44,0.65)$. Factor 6 was the basal substrate oxidation rates (glucose oxidation rate -0.94 ; lipid oxidation rate 0.91 ). Factor 7 was the basal serum insulin (0.76; for comparison plasma insulin levels at 120 minutes after glucose load: 0.48 ). Factor 8 was the protein oxidation rate ( 0.91$)$ and finally, factor 9 was the duration of disease $(r=0.80)$.

In addition to varimax analysis, two stepwise multivariate regression analyses were performed. First, using the plasma glucose concentration at 120 minutes after glucose load as the dependent variable, about $54 \%$ of its variability could be explained by the quantities tested; the following $r^{2}$ values were obtained: 0.36 for basal glucose concentration, 0.05 for basal free fatty acid levels, 0.04 for age, 0.03 for basal glucose oxidation, 0.03 for muscle mass, 0.03 for plasma free glycerol levels at 120 minutes after glucose load and 0.02 for the CHILD score. Second, using the serum insulin concentration at 120 minutes after glucose load about $35 \%$ of its variance could be explained by the quantities tested; the following $\mathrm{r}^{2}$ values were obtained: 0.18 for basal serum insulin concentration, 0.09 for fat mass, 0.05 for muscle mass and 0.04 for the plasma glucose concentration at 120 minutes after glucose load.

\section{Discussion}

Glucose intolerance is frequently seen in cirrhotic patients. Thirty-six percent of our patients had impaired glucose tolerance and $37 \%$ were diabetic (fig. 1). However, $27 \%$ of the patient group had normal glucose tolerance curves (fig. 1). The reasons for this variance of glucose metabolism observed in cirrhosis are unclear. Our cross-sectional study addresses a number of factors considered to be important for the clinical characterisation of patients with liver cirrhosis. Stepwise regression analysis suggests that the aetiology and duration of cirrhosis, the clinical state, biochemical indicators of hepatocyte damage and/or liver function are of minor importance for glucose tolerance after the manifestation of the disease (see results). This does not contradict the idea that postprandial (120 minutes after glucose load) glucose concentrations may be increased in subgroups of patients with a more pronounced reduction of liver function, as assessed by the use of quantitative liver function tests (tab. 3). However, the prevalence of glucose intolerance does not regularly increase with deteriorating clinical state (tab. 2). Furthermore, varimax analysis shows that the clinical and biochemical measures of 
Tab. 4 Nutritional and metabolic state of patients with liver cirrhosis and different degrees of glucose tolerance.

Glucose tolerance

\begin{tabular}{lll}
\hline normal & impaired & diabetic \\
$n=29$ & $n=39$ & $n=40$
\end{tabular}

\section{Nutritional state}

Height $(\mathrm{cm})$

Weight $(\mathrm{kg})$

Triceps skinfold thickness (mm)

Corrected arm muscle area')

Muscle mass $\left.{ }^{2}\right)(\mathrm{kg})$

Fat free mass $\left.{ }^{3}\right)(\mathrm{kg})$

Body cell mass $\left.{ }^{3}\right)(\mathrm{kg})$

Fat $\left.\operatorname{mass}^{3}\right)(\mathrm{kg})$

$\begin{array}{rr}169.7 \pm & 10.7 \\ 66.0 \pm & 17.8 \\ 11.3 \pm & 5.6 \\ 33.3 \pm & 13.3 \\ 20.4 \pm & 10.5 \\ 50.3 \pm & 14.6 \\ 23.7 \pm & 7.6 \\ 16.1 \pm & 6.5\end{array}$

$1861 \pm 374$

$7816 \pm 1571$

$16.8 \pm 14.1$

$71.7 \pm 15.3$

$11.5 \pm \quad 7.3$

$\begin{array}{rr}170.5 \pm & 9.6 \\ 69.2 \pm & 14.5 \\ 13.1 \pm & 8.1 \\ 32.2 \pm & 9.4 \\ 20.8 \pm & 8.7 \\ 50.8 \pm & 12.2 \\ 23.8 \pm & 8.0 \\ 17.9 \pm & 7.9\end{array}$

$1915 \pm 367$

$8043 \pm 1541$

$12.7 \pm 12.4$

$74.1 \pm 13.6$

$13.2 \pm 5.3$
$169.7 \pm \quad 7.7$

$68.8 \pm 13.5$

$12.6 \pm 7.1$

$32.6 \pm 11.4$

$20.6 \pm \quad 7.3$

$51.0 \pm 10.6$

$23.2 \pm 6.0$

$17.8 \pm 6.6$

Lipid oxidation rate $\left.\left.(\% \mathrm{REE})^{4}\right)^{5}\right)$

Protcin oxidation rate $\left.(\% \mathrm{REE})^{4}\right), 5$ )

$\left.{ }^{3}\right)$ calculated from data obtained by bioelectrical impedance analy-

1) (muscle arm circumference $-3.14 \times$ triceps skinfold thickness/

$4 \times 3.14$ ) -10 (male) or -6.5 (female) (according to (26))

$\left.{ }^{2}\right)$ calculated from $7.38+0.029 \times 113.2 \times(24 \mathrm{~h}$ urinary creatinine excretion in $\mathrm{mmol} / \mathrm{d}$ ) (according to 1 . c. (22) and (26)) sis (see I. c. $(17,20)$ )

4) fraction of resting energy expenditure, $\%$

s) calculated as given in 1. c. (12)

liver function are independent of the nutritional and metabolic quantities tested (see results). Impaired glucose tolerance is also seen in patients with acute viral hepatitis $(20-23)$, in a patient with presinusoidal portal hypertension (24) and in patients with fatty liver (25) without histological signs of liver cirrhosis. These findings suggest that liver injury and/or altered hepatic circulation, but not cirrhosis itself, are the initiating events of glucose intolerance. Interestingly, cirrhotics with a normal glucose tolerance do not develop glucose intolerance within the subsequent 5 years of observation (25).

Although glucose intolerance is not associated with the clinical markers of liver disease, it is associated with metabolic factors, such as basal plasma glucose concentrations, basal glucose oxidation rate and plasma free glycerol concentrations at 120 minutes after glucose load. Obviously these factors are for the most part other markers of the metabolic disturbance and thus cannot be considered as causative. Malnutrition (i. e. a reduced muscle mass) also reached significance in our stepwise regression analysis (see results). This is in line with previous data, showing that reduced muscle mass is associated with a reduced glucose disposal, using the euglycaemic-hyperinsulinaemic clamp technique or the minimal model assessment in smaller groups of cirrhotics $(10,12)$. With regard to changes in body composition, some patients with cirrhosis show an increased fat mass (fig. 5). These patients are markedly hyperinsulinaemic (fig. 5). A close association was found between postprandial (120 minutes after glucose load) hyperinsuli- naemia and fat mass in cirrhotic patients (see results). Although not conclusive, these data support our hypothesis that hyperinsulinaemia contributes to changes in body composition in patients with liver cirrhosis (26).

Advanced age is also known to increase the prevalence of glucose intolerance and non-insulin dependent diabetes mellitus in most populations (27). This is also true in cirrhotic patients (fig. 6). Prevalence represents the balance between the development of new cases and the effect of mortality among those with diabetes mellitus. Since longitudinal studies are lacking, one has to consider the possibility that the occurrence of cirrhosis plus diabetes mellitus may affect the mortality of patients with cirrhosis. However, it is unlikely that the occurrence of diabetes mellitus plus cirrhosis significantly reduces mortality. We therefore take our data as evidence that advanced age contributes to the manifestation of glucose intolerance and diabetes mellitus in cirrhotic patients (fig. 6).

There is a close association between plasma glucose and plasma insulin levels in patients with cirrhosis, as well as in controls, showing an increase in insulin concentration with increasing glucose concentration up to a plasma glucose level of 8 to $10 \mathrm{mmol} / 1$ (fig. 4). This association has been described as the "Starling curve" of the pancreas (28). Obviously, this mechanism is operative in cirrhotic and non-cirrhotic subjects. Plasma insulin levels are higher in cirrhotic than in non-cirrhotic subjects over the whole range of plasma glucose concen- 

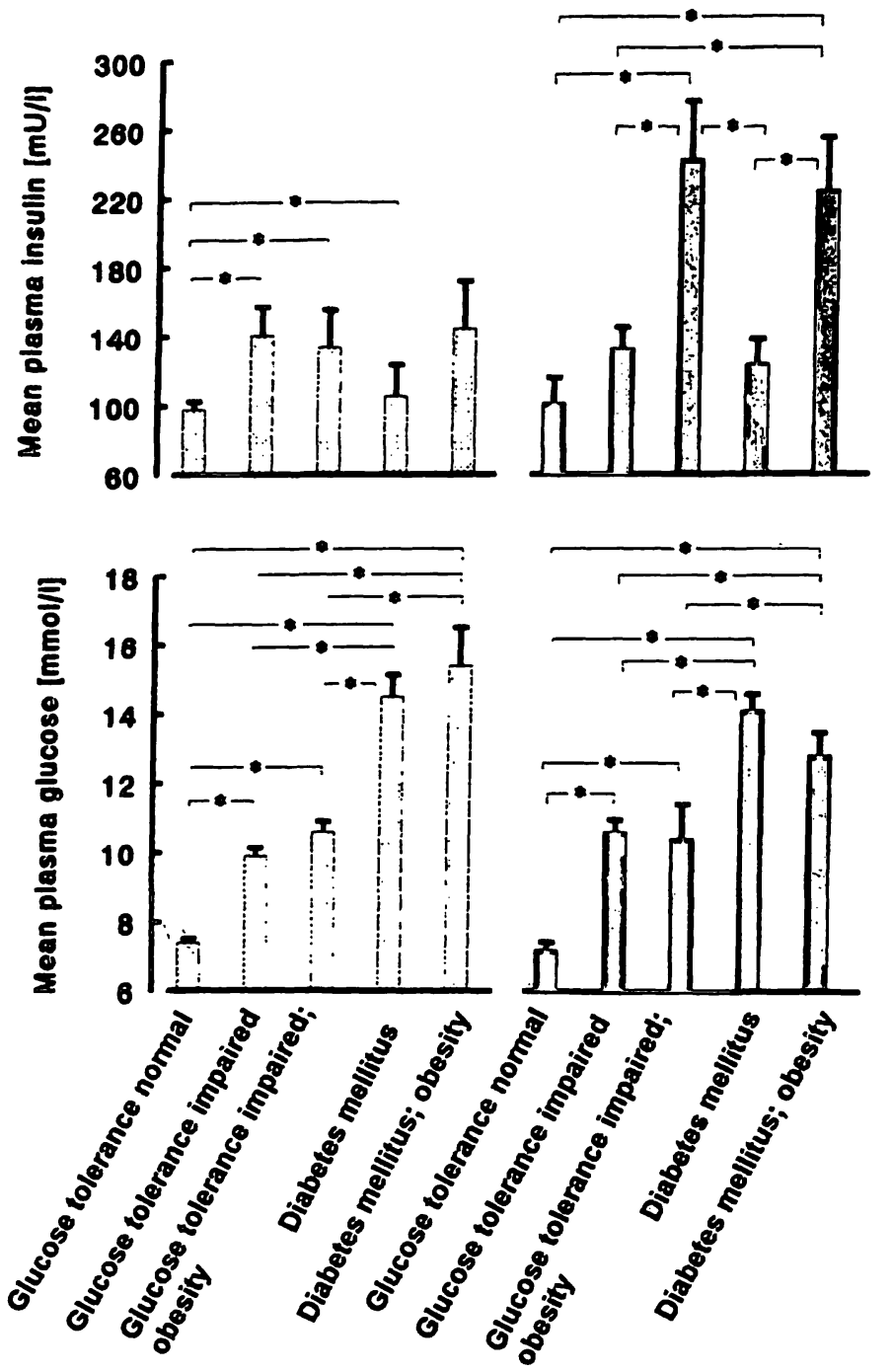

Fig. 5 Mean insulin and glucose levels during oral glucose tolerance test in subgroups of controls and patients.

Mean "postprandial" (120 minutes after glucose load) plasma insulin and glucose concentrations in controls [0] and patients with liver cirrhosis [ $\square$ ] differing with respect to glucose tolerance. Obesity was defined as a fat mass representing more than $30 \%$ of body weight. Data are means \pm SEM. Significant differences are indicated by $*(p<0.05)$.

trations. It is tempting to speculate that the increased insulin response seen in cirrhosis results from increased insulin secretion plus decreased hepatic insulin extraction $(10,29-31)$. The contribution of these two quantities is variable and differs between different patients. The insulin/C-peptide ratio is a rough measure of portosystemic shunting of insulin, but can also be used under steady state conditions (i. e. in the basal state) in cirrhosis (30; fig. 2). Our data suggest an increased portosystemic shunting of insulin in the majority of cirrhotic patients. Concomitantly, insulin secretion seems to be normal or enhanced as reflected by plasma $C$-peptide levels (fig. 2).

Secondary diabetes observed in liver diseases is considered to be an acquired phenomenon (32). It is tempting to speculate that cirrhotics with a genetic predisposition for type 2 diabetes mellitus are prone to develop glucose intolerance with the manifestation of liver disease. However, patients with a positive family history of diabetes mellitus do not show an increased frequency of glucose intolerance (see results). These data provide evidence for the idea that diabetes mellitus associated with liver cirrhosis is unrelated to non-insulin dependent diabetes mellitus. Further evidence for this idea comes from a number of experimental and clinical studies (11, 3437). In contrast to patients with non-insulin dependent diabetes mellitus, cirrhotics only show peripheral, but not hepatic insulin resistance $(35,38)$. Peripheral insulin resistance in cirrhosis is characterised by decreased glucose transport (37) and reduced glycogen synthesis in skeletal muscle $(33-36)$, whereas the insulin-induced increases in glucose phosphorylation (37), glycolysis (11) and glucose oxidation $(34,35,38)$ are normal in cirrhosis. In contrast, glucose transport, glucose phosphorylation, glycolysis, glucose oxidation and glycogen synthesis are all impaired in type 2 diabetes mellitus (39,

\section{Liver cirrhosis}

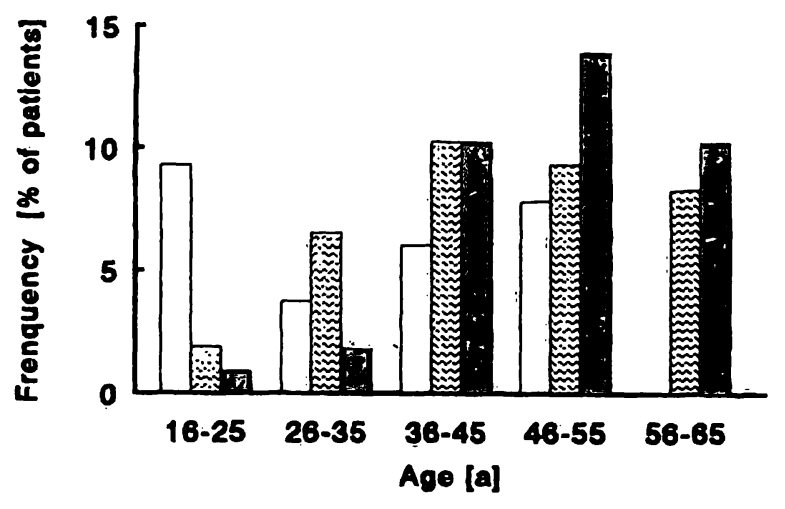

\section{Controls}

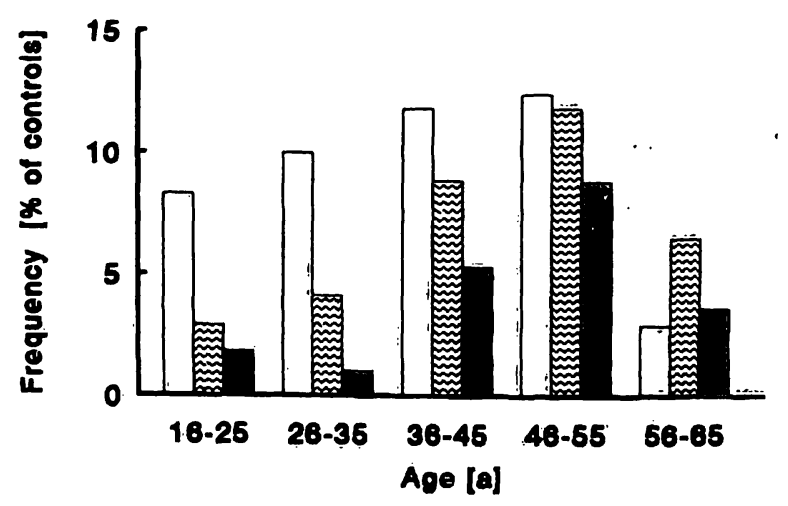

Fig. 6 Percentage distribution of patients and controls with normal, impaired or diabetic glucose tolerance in different age groups. $\left[\square\right.$ normal glucose tolerance, ${ }^{2}$ impaired glucose tolerance, $\mathbf{D}$ dia- 
40). Marked hyperinsulinaemia normalises glycogen synthesis and the total flux through glycolysis, but does not restore a normal distribution between glucose oxidation and anaerobic glycolysis in diabetic subjects (40). In cirrhosis, pharmacological amounts of insulin are not capable of normalising glycogen synthesis but they disproportionally increase lactate production (11). Thus, when comparing non-insulin dependent diabetes mellitus with cirrhosis, considerable differences in the metabolic picture are obvious.

The variance in oral glucose tolerance observed in cirrhosis differs from the data obtained in clamp studies, in which the majority if not all cirrhotics show peripheral insulin resistance. To explain the different results, a number of influences have to be discussed. First, compensatory increases in insulin secretion may compensate for peripheral insulin resistance, resulting in a normal oral glucose tolerance curve in some cirrhotics (30). Se- cond, during a clamp study, skeletal muscle is responsible for 60 to $85 \%$ of whole body glucose disposal in controls, patients with non-insulin dependent diabetes mellitus (28) and in cirrhosis (37). However, muscle accounts for only $25 \%$ of glucose disposal after an oral glucose load, while storage in muscle accounts for less than $10 \%$ of the load (41). Thus, defective glucose storage probably plays a small role in the overall disposal of an oral glucose load. Third, differences in first pass hepatic uptake of glucose are of minor importance during an euglycaemic clamp study.

\section{Acknowledgements}

The authors thank Mrs. Mechthild Schwarze, Dietlinde Baars and Dagmar Becker for technical assistance and Mr. Joachim Lobers for his help in performing the statistical analyses. This work was supported by the B. Braun Stiftung and B. Braun Melsungen, Melsungen, Germany.

\section{References}

1. Creutzfeld, W., Hartmann, H., Nauck, M. \& Stöckmann, F. (1983) Liver disease and glucose homoiostasis. In: Liver in Metabolic Diseases (Bianchi, L., Gerok, W., Landmann, L., Sickinger, K. \& Stalder, G. A., eds.) pp. 221-234, MTP press, Boston, MA, USA.

2. Marchesini, G., Bianchi, G. P., Zoli, M. \& Chechia, G. A. (1987) Glucose homoiostasis in cirrhosis. In: Cirrhosis of the Liver: Methods and Fields of Research (Tygstrup, N. \& Orlandi, F., eds.) pp. 165-176, Elsevier, Amsterdam.

3. Petrides, A. \& DeFronzo, R. A. (1989) Glucose metabolism in cirrhosis: A review with some perspectives for the future. Diabetes and Metabolism 5, 691-709.

4. Schmueli, E., Record, C. O. \& Alberti, K. G. M. M. (1992) Liver disease, carbohydrate metabolism and diabetes. Bull. Clin. Endocrinol. Metab. 6, 719-743.

5. Taylor, R., Johnston, D. G. \& Alberti, K. G. M. M. (1985) Insulin action in cirrhosis. Hepatology 5, 64-71.

6. McIntyre, N. (1987) Undernutrition and malnutrition in cirrhosis. In: Cirrhosis of the Liver: Methods and Fields of Research (Tygstrup, N. \& Orlandi, F., eds.) pp. 225-234, Elsevier, Amsterdam.

7. Porayko, M. K., DiCecco, S. \& O'Keefe, S. J. D. (1991) Impact of malnutrition and its therapy on liver transplantation. Seminars in Liver Disease $11,305-314$.

8. Lautz, H. U., Selberg, O., Körber, J., Bürger, M. \& Müller, M. J. (1992) Protein-calorie malnutrition in liver cirrhosis. Clin. Invest. 70, 478-486.

9. Yki-Järvinen, H. \& Koivisto, V. A. (1983) Effects of body composition on insulin sensitivity. Diabetes 32, 965-969.

10. Marchesini, G., Pacini, G., Bianchi, C., Patrono, D. \& Cobelli, C. (1990) Glucose disposal, $\beta$-cell secretion, and hepatic insulin extraction in cirrhosis: A minimal model assessment. Gastroenterology 99, 1715-1722.

11. Müller, M. J., Willmann, O., Rieger, A., Fenk, A., Selberg, O., Lautz, H. U., Bürger, M., Balks, H. J., von zur Mühlen, A. \& Schmidt, F. W. (1992) Mechanism of insulin resistance associated with liver cirrhosis. Gastroenterology 102, 2033-2041.

12. Müller, M. J., Lautz, H. U., Plogmann, B., Bürger, M., Körber, J. \& Schmidt, F. W. (1992) Energy expenditure and substrate oxidation in patients with cirrhosis: The impact of cause, clinical staging and nutritional state. Hepatology 15, 782-794.
13. Pugh, R. N. H., Murray-Lyon, I. M., Dawson, J. L., Pietron, M. C. \& Will, R. (1973) Transsection of the oesophagus for bleeding oesophageal varices. Br. J. Surg. 60, 646-649.

14. Lautz, H. U. \& Pichlmayr, R. (1989) Special aspects of timing of liver transplantation in patients with liver cirrhosis. Bull. Clin. Gastroenterol. 3, 743-756.

15. Oellerich, M., Raude, E., Burdelski, M., Schulz, M., Schmidt, F. W., Ringe, B., Lamesch, P., Pichlmayr, R., Schwerun, M., Wrenger, M., Wittekind, C., Klawuhn, B., Knoke, A., Mauz, M. \& Farle, M. (1987) Monoethylglycinexylidide formation kinetics: A novel approach to assessment of liver function. J. Clin. Chem. Clin. Biochem. 25, 845-853.

16. Guglielmi, F., Contuto, F., Caddaga, L., Panella, C. \& Francavilla, A. (1991) Bioelectrical impedance analysis. Experience with male patients with cirrhosis. Hepatology 13, 892-895.

17. Zillikens, M. C., van den Berg, J. W. O., Wilson, J. H. P. \& Swart, G. R. (1992) Whole body and segmental bioelectrical impedance analysis in patients with cirrhosis of the liver: Changes after treatment of ascites. Am. J. Clin. Nutr. 55, $621-625$.

18. Müller, M. J., Selberg, O., Süttmann, U., Weimann, A. \& Kuse, E. R. (1992) Schätzung und Messung des Energieverbrauches: Methoden und Stellenwert in der klinischen Diagnostik. Intensivmedizin 29, 411-426.

19. Müller, M. J., Rieger, A., Willmann, O., Lautz, H. U., Balks, H. J., von zur Mühlen, A., Canzler, H. \& Schmidt, F. W. (1992) Metabolic responses to lipid infusions in patients with liver cirrhosis. Clin. Nutr. 11, 193-206.

20. Botterman, P., Zilker, T., Ermler, R., Paterek, K. \& Stransky, B. (1978) C-Peptid und Insulinkonzentration im Serum bei akuter Virushepatitis. Klin. Wochenschrift 56, 1029-1032.

21. Chupin, M., Charbonnel, B. LeBondic, L., Grolleau, J. Y., Chupin, F. \& Guillon, J. (1978) Glucose tolerance in viral hepatitis. A study of twenty patients during acute phase and recovery. Diabetes 27, 661-669.

22. Granot, C., Bar-On, H. \& Shafrir, E. (1981) Patterns of glucose intolerance and free fatty acid behaviour in viral hepatitis. Isr. J. Med. Sci. 17, 12-18.

23. Kelch, L., Adlung. J., Babaian, A. \& Jaensch, H. (1981) Verhalten der Glukosetoleranz, des Seruminsulins und C-Peptides im Verlaur einer akuten Virushepatitis. Deutsche Z. Verdauungs- und Stoffwechselkrankhciten $41,134-143$. 
24. Petrides, A. S., Riely, C. A. \& DeFronzo, A. (1991) Insulin resistance in non-cirrhotic idiopathic portal hypertension. Gastroenterology 100, 245-251.

25. Oehler, G. (1985) Glukosetoleranzstörungen bei Lebererkrankungen. Aktuelle Ernährungsmedizin 10, 115-119.

26. Müller, M. J., Willmann, O., Fenk, A., Rieger, A., Selberg, O., Danzler, H., von zur Mühlen, A. \& Schmidt, F. W. (1992) Resting energy expenditure and the thermic effect of adrenaline in patients with cirrhosis. Clin. Science 83, 191-198.

27. Benett, P. H., Bogardus, C., Tuomilehto, J. \& Zimmet, P. (1992) Epidemiology and natural history of NIDDM: Nonobese and obese. In: International Textbook of Diabetes Mellitus (Alberti, K. G. M. M., DeFronzo, R. A., Keen, H. \& Zimmet, P., eds.) pp. 147-176, J. Wiley \& Sons, Chichester.

28. DeFronzo, R. A., Bonadonna, R. \& Ferrannini, E. (1992) Pathogenesis of NIDDM. Diabetes Care 15, 318-368.

29. Ballmann, M., Hartmann, H., Daecon, C. F., Schmidt, W. E., Conlon, J. M. \& Creutzfeld, W. (1986) Hypersecretion of proinsulin does not explain the hyperinsulinaemia of patients with liver cirrhosis. Clin. Endocrinol. 25, 351-361.

30. Kruszynska, Y. T., Home, P. D. \& McIntyr, N. (1991) Relationship between insulin sensitivity, insulin secretion and glucose tolerance in cirrhosis. Hepatology 14, 103-111.

31. Kruszynska, Y. T., Harry, D. S., Bergman, R. N. \& McIntyre, $N$. (1993) Insulin sensitivity, insulin secretion and glucose effectiveness in diabetic and non-diabetic cirrhotic patients. Diabetologia : $36,121-128$.

32. Petrides, A. S., Strohmeyer, G., DeFronzo, R. A. (1992) Insulin resistance in liver disease and portal hypertension. Progress in Liver Diseases 19, 311-328.

33. Kruszynska, Y., Williams, N., Perry, M. \& Home, P. (1988) The relationship between insulin sensitivity and skeletal muscle enzyme activities in liver cirrhosis. Hepatology 8, 16151619.

34. Müller, M. J., Fenk, A., Lautz, H. U., Selberg, O., Canzler, H., Balks, H. J., von zur Mühlen, A., Schmidt, E. \& Schmidt, F. W. (1991) Energy expenditure and substrate metabolism in ethanol-induced liver cirrhosis. Am. J. Physiol. 260, E338E344.
35. Petrides, A., Groop, L. C., Riely, C. A. \& DeFronzo, R. A. (1991) Effect of physiologic hyperinsulinemia on glucose and lipid metabolism in cirrhosis. J. Clin. Invest. 88, 561-570.

36. Meyer-Alber, A., Hartmann, H., Stümpel, F., Creutzfeld, W. (1992) Mechanism of insulin resistance in $\mathrm{CCl}_{4}$-induced cirrhosis of rats. Gastroenterrology 102, 223-229.

37. Selberg, O., Burchert, W., v. d. Hoff, J., Meyer, G. D., Radoch, E., Hundeshagen, H., Balks, H. J. \& Müller, M. J. (1993) Insulin resistance in liver cirrhosis: A PET scan analysis of skeletal muscle glucose metabolism. J. Clin. Invest. 91, 1897-1902.

38. Kruszynska, Y. T., Meyer-Alber, A., Darakhshan, F., Home, P. D. \& McIntyre, N. (1993) Metabolic handling of orally administered glucose. J. Clin. Invest. 91, 1057 $=1066$.

39. Thorburn, A. W., Gumbiner, W., Bulacan, F., Wallace, P. \& Henry, R. R. (1990) Intracellular glucose oxidation and glycogen synthase activity are reduced in non-insulin dependent (type II) diabetes independent of impaired glucose tolerance. J. Clin. Invest. 85, 522-529.

40. DelPrato, S., Bonadonna, R. C., Bonora, E., Gulli, G., Solini, A., Shänk, M. \& DeFronzo, R. A. (1993) Characterization of insulin action in type 2 (non-insulin-dependent) diabetes mellitus. J. Clin. Invest. 91, 484-493.

41. Kelley, D., Mitrakou, A., Marsh, H., Schwenk, F., Benn, J., Sonnenberg, G., Arcangeli, M., Aoki, T., Sorensen, J., Berger, M., Soenksen, P. \& Gerich, J. (1988) Skeletal muscle glycolysis, oxidation and storage of an oral glucose load. J. Clin. Invest. $81,1563-1571$.

42. National Diabetes Data Group (1979) Classification and diagnosis of diabetes mellitus and other categories of glucose intolerance. Diabetes 28, 1039-1057.

Prof. Dr. M. J. Müller

Institut für Humanernährung

und Lebensmittelkunde

Christian-Albrechts-Universität zu Kiel

Düsternbrooker Weg 17

D-24105 Kiel

Germany 